\title{
Characterizing effects of mild traumatic brain injury and posttraumatic stress disorder on balance impairments in blast-exposed servicemembers and Veterans using computerized posturography
}

\author{
Joanna R. Wares, PhD; ${ }^{1 *}$ Kathy W. Hoke, PhD; ${ }^{1}$ William Walker, MD; ${ }^{2-3}$ Laura Manning Franke, PhD; ${ }^{2-3}$ \\ David X. Cifu, MD; ${ }^{2}$ William Carne, PhD; ${ }^{2}$ Cheryl Ford-Smith, PT, DPT, MS, NCS ${ }^{4}$ \\ ${ }^{1}$ Department of Mathematics and Computer Science, University of Richmond, Richmond, VA; ${ }^{2}$ Department of Physical \\ Medicine and Rehabilitation, Virginia Commonwealth University, Richmond, VA; ${ }^{3}$ Defense and Veterans Brain Injury \\ Center, Department of Veterans Affairs, Richmond, VA; ${ }^{4}$ Department of Physical Therapy, Virginia Commonwealth \\ University, Richmond, VA
}

\begin{abstract}
The high rate of blast exposures experienced by U.S. servicemembers (SMs) during the recent conflicts in Iraq and Afghanistan has resulted in frequent combat-related mild traumatic brain injuries (mTBIs). Dizziness and postural instability can persist after mTBI as a component of postconcussion syndrome, but also occur among the somatic complaints of posttraumatic stress disorder (PTSD). The goals of this study were to examine the use of computerized posturography testing (CPT) to objectively characterize chronic balance deficits after mTBI and to explore the utility of CPT in distinguishing between combat and blast-exposed participants with and without mTBI and PTSD. Data were analyzed from a subject pool of 166 combatexposed SMs and Veterans who had a blast experience within the past $2 \mathrm{yr}$ while deployed. Using nonparametric tests and measures of impairment, we found that balance was deficient in participants diagnosed with mTBI with posttraumatic amnesia (PTA) or PTSD versus those with neither and that deficits were amplified for participants with both diagnoses. In addition, unique deficiencies were found using CPT for individuals having isolated mTBI with PTA and isolated PTSD. Computerized balance assessment offers an objective technique to examine the physiologic effects and provide differentiation between participants with combat-associated mTBI and PTSD.
\end{abstract}

Key words: balance, balance impairment, blast exposure, computerized posturography, impairment, mild traumatic brain injury, posttraumatic amnesia, posttraumatic stress disorder, servicemembers, Veterans.

\section{INTRODUCTION}

In Operation Iraqi Freedom (OIF), Operation Enduring Freedom (OEF), and Operation New Dawn (OND), U.S. servicemembers (SMs) have been subjected to a high

\begin{abstract}
Abbreviations: BESQ = Blast Experience Screening Questionnaire; $\mathrm{COM}=$ center of mass; $\mathrm{COMP}=$ composite score; $\mathrm{CPT}=$ computerized posturography testing; $\mathrm{EQ}=$ equation; $\mathrm{DSM}=$ Diagnostic and Statistical Manual of Mental Disorders; MCB = Marine Corps Base; MINI = Mini-International Neuropsychiatric Interview PTSD module; $\mathrm{mTBI}=$ mild traumatic brain injury; $\mathrm{OEF}=$ Operation Enduring Freedom; OIF = Operation Iraqi Freedom; OND = Operation New Dawn; PCL-C = PTSD Checklist, Civilian version; $\mathrm{PCS}=$ postconcussion syndrome; PTA = posttraumatic amnesia; PTSD = posttraumatic stress disorder; $\mathrm{SM}=$ servicemember; $\mathrm{SOT}=$ Sensory Organization Test; $\mathrm{TBI}=$ traumatic brain injury; VA = Department of Veterans Affairs; VAMC = VA Medical Center; VCU rCDI-B = Virginia Commonwealth University retrospective Concussion Diagnostic Interview-Blast version.

*Address all correspondence to Joanna R. Wares, PhD; Department of Mathematics and Computer Science, University of Richmond, 28 Westhampton Way, Richmond, VA 23173; 804-287-6564; fax: 804-287-6444.
\end{abstract}

Email: jwares@richmond.edu

http://dx.doi.org/10.1682/JRRD.2014.08.0197 
rate of blast exposures, with explosive munitions accounting for 78 percent of wounded in action cases, the highest proportion for any large-scale conflict [1]. Traumatic brain injury (TBI) is one of the consequences of these blast exposures and is considered the "signature wound" of the OIF/OEF/OND conflicts. Among deployed SMs and Veterans, 19 percent are estimated to have sustained a TBI [2]. Mild TBI (mTBI), or concussion, is by far the most common category of TBI during these deployments, accounting for over 80 percent of cases [3], and up to 20,000 additional mTBIs occur in garrison annually [4]. Although indexed as mild based on initial severity, nearly 20 percent of those sustaining mTBI will develop postconcussion syndrome (PCS), a condition of persistent symptoms ( $\geq 3 \mathrm{mo}$ ) that may include physical, cognitive, and behavioral impairments [5-6].

Among the many potential consequences of TBI, the effects of imbalance are some of the more impactful on functional status, including capacity to return to work [7]. Balance, or postural stability, is defined as the ability to maintain the body's center of gravity within the base of support with minimal postural sway [8]. To achieve balance, input from multiple sensory components - visual, proprioceptive, and vestibular-must be integrated and coordinated with the motor system via the cerebellum [9]. Subjective dizziness and postural instability (imbalance) are common acutely and chronically after moderate-tosevere TBI [10], as well as mTBI, where they can persist chronically as components of PCS [11]. In moderate-tosevere TBI, objective impairment of early balance function is ubiquitous, can be measured on routine physical examination, and is predictive of rehabilitation outcome [12-13]. Objective balance impairments persisting months to years after moderate-to-severe TBI have also been documented on computerized posturography testing (CPT), a method of quantifying balance through body weight shifts on a force plate under normal and altered sensory conditions [14]. The Sensory Organization Test (SOT) is a component of CPT that measures information about the integration of the sensory components of standing balance (visual, proprioceptive, and vestibular) and generates an outcome measure called the equilibrium score that assesses the overall coordination of these systems to maintain standing posture [9]. In sports-related mTBI, objective balance deficits have been shown acutely ( $1 \mathrm{wk}$ ) and subacutely (up to $90 \mathrm{~d}$ ) compared with both baseline and controls using either the SOT [15-16], the Balance Error Scoring System [17], or the center of mass (COM) during gait [18]. Findings on the SOT, COM, and Dizziness Handicap Inventory, a subjec- tive measure of dizziness, have been shown to be significantly interrelated in the assessment of balance after TBI [19]. In one investigation, participants with acute mTBI had higher magnitudes of sway when deprived of accurate visual cues, despite having no gross visual or neurologic impairments, leading researchers to comment on the subtle complexity and need for central integration of the multisensory contributions to balance [20-21]. Importantly, however, in these mTBI studies, the differences typically resolved within the first several weeks to months [22-24]. While there are an increasing number of small studies showing static or dynamic balance deficits following sports-related mTBI in the acute (1 wk) and subacute (1$12 \mathrm{wk}$ ) periods [18,20-23], there are no large-scale, wellcontrolled sports or trauma studies measuring objective balance deficits after mTBI beyond this time frame [20].

Veterans and SMs with blast exposure and suspected mTBI also commonly report persistent dizziness, vertigo, clumsiness, and imbalance symptoms [11,25-26]. However, data on objective postural stability in this population are sparse and generally lacking controls. Vanderploeg et al. demonstrated impaired tandem gait in Vietnam war Veterans with chronic dizziness after mTBI compared with controls [27]. However, this study used archival data and self-identified mTBI, so the validity of the findings is unclear. In a case series of OIF/OEF/OND SMs with blastassociated mTBI, Hoffer et al. reported an 84 percent incidence of acute dizziness symptoms and a substantial portion had abnormal CPT-SOT scores more than $30 \mathrm{~d}$ after injury [28]. Similarly, a range of studies without control comparisons have reported that between 46 and 74 percent of symptomatic Veterans with blast-associated mTBI of even longer duration (months to years postinjury) had abnormal SOT scores [29-31].

The frequency of comorbidities associated with combat mTBI [32], which may also be linked to balance deficits, further complicates the identification of a consistent pattern of balance deficits corresponding to blast-related mTBI. One of the most significant unstudied potential confounders for military populations is posttraumatic stress disorder (PTSD), which is found in up to one-third of OIF/ OEF/OND combatants [33]. Chronic dizziness is a common symptom among individuals with combat-associated PTSD [34]. Although published CPT data are lacking for PTSD, it is well documented that postural instability is associated with anxiety disorders in general [35].

In summary, the objectivity of assessment provided by CPT may offer a means of both identifying and monitoring recovery of individuals with mTBI-associated 
balance deficits. But the few published studies that examine balance impairments in SMs and Veterans with mTBI have lacked appropriate controls with a history of combat deployment and blast exposure and have not examined confounding factors such as PTSD. This raises questions about the confounding role of other combat and blastrelated conditions in the findings to date, as well as the utility of objective CPT findings to either support the mTBI diagnosis or monitor recovery from mTBI. In this investigation, we sought to characterize balance deficits after combat blast exposure (with and without TBI and/or PTSD) and to address the utility of using CPT to differentiate blast-exposed individuals with no diagnosed injury, mTBI, PTSD, or co-occurring mTBI and PTSD. We hypothesized that there would be a unique pattern of balance deficits defined by CPT for individuals with chronic mTBI when compared with controls or individuals with PTSD.

\section{METHODS}

\section{Participants}

Participants were recruited via letters and advertisements and from ambulatory healthcare clinics at the Hunter Holmes McGuire Department of Veterans Affairs (VA) Medical Center (VAMC) in Richmond, Virginia; Fort Lee Army Base in Prince George County, Virginia; Quantico Marine Corps Base (MCB) in Prince William County, Virginia; and Camp Lejeune MCB in Jacksonville, North Carolina. SMs and Veterans were eligible if they had a blast experience within the past $2 \mathrm{yr}$ while deployed in OIF/ $\mathrm{OEF} / \mathrm{OND}$. After approval from the institutional review boards of each institution/facility and approval from the Department of Defense's Human Research Protection Office, eligible participants who consented to inclusion in the study were evaluated. Blast experience was defined as having any of the following symptoms or experiences during or shortly after exposure to blast or explosion: dazed, confused, saw stars, headache, dizziness, irritability, memory gap (not remembering injury or injury period), hearing loss, abdominal pain, shortness of breath, struck by debris, knocked over or down, knocked into or against something, helmet damaged, or medically evacuated. Severe and moderate TBI were the only exclusion criteria and were defined as more than $30 \mathrm{~min}$ in coma, brain bleeding or blood clot (abnormal brain computed tomography scan), or none of first 24 or more hours after event remembered (posttraumatic amnesia $[\mathrm{PTA}]>24 \mathrm{~h}$ ). Therefore, participants either had blast exposure without sustaining TBI or had sustained at least one blast-related mTBI.

As part of a larger, prospective longitudinal investigation, all participants underwent a comprehensive baseline assessment to collect demographic information; medical history including injuries and care received during their military service; specifics of blast exposure, injury, care, and sequelae; and current symptoms and level of functioning. For this initial exploratory study, the associations between data on injury diagnoses, presence of mTBI and PTSD, and balance testing were analyzed. Based on the availability and time constraints and burden of the subjects in this longitudinal investigation, the baseline assessment was accomplished in one of two ways: standardized interviews or checklist/questionnaires. We categorized 107 participants with mTBI and/or PTSD using the Virginia Commonwealth University retrospective Concussion Diagnostic Interviewblast version (VCU rCDI-B) and the Mini-International Neuropsychiatric Interview PTSD module (MINI; version 6.0), respectively. Interview data were not available for the remaining 62 participants, and so mTBI and PTSD status for these participants was determined using the Blast Experience Screening Questionnaire (BESQ) and PTSD Checklist, Civilian version (PCL-C), respectively.

The VCU rCDI-B is a combined unstructured and fully structured interview designed to affirm the presence of a blast-associated mTBI, either with or without PTA. For those with multiple blast-related experiences, the selfidentified "worst" potential concussive event was selected for interview. The interview data were independently reviewed by five experienced TBI physicians who individually rated each blast exposure in reference to the Department of Defense/VA common definition for mTBI [36]. A consensus diagnosis was obtained for each participant based on the physician majority rating. The BESQ is a modified version of the Walter Reed Army Medical Center Blast Injury Questionnaire, which characterizes blast effects [37]. Similar to the VCU rCDI-B interview, an algorithm using the combination of the alteration of consciousness items from the BESQ was used on the noninterviewed subset that gave the peak kappa $(\mathrm{k}=0.59,91 \%$ correctly classified) versus the physician consensus among the interviewed subset. Further, based on our clinical experience and supporting data from the athletic mTBI literature [36], we hypothesized that those having mTBI with PTA would be most likely to experience long-term impairment commonly associated with blast injury. Using interview and BESQ data, we divided the participants with mTBI into 
those with PTA and those without PTA. The diagnosis of mTBI with PTA is referred to in the analyses as "blast mTBI," and the group with mTBI without PTA was combined with those diagnosed to have not sustained mTBI and referred to as "no blast mTBI." The MINI is a validated, short, structured diagnostic interview based on Diagnostic and Statistical Manual of Mental Disorders (DSM)-IV and International Classification of Diseases-9th Revision criteria that was developed by psychiatrists and clinicians jointly in the United States and Europe [38]. Each participant's PTSD diagnosis was determined using "relaxed" DSM-IV criteria that ignored the A2 criterion and simulates DSM-V [30]. The PCL-C is a validated and widely used measure of self-reported PTSD symptom severity [39-40]. It should be noted that the items and Likert values on the civilian version are identical to the military version; the civilian version was chosen to avoid assuming that all individuals' most stressful life event was during combat. For the PCL-C, $\geq 58$ was used to define PTSD because this cutpoint gave the peak kappa value $(\mathrm{k}=0.54,81 \%$ correct classification rate) in analysis of its receiver operating characteristics versus the MINI within the 107 interviewed participants [39].

\section{Outcome Measures}

All participants underwent complete balance testing regardless of underlying injury or diagnosis, history of dizziness or imbalance, or current difficulties. Postural stability and balance were measured with CPT on a dual-plate force platform, the NeuroCom Smart Balance Master (NeuroCom International Inc; Clackamas, Oregon). The specific CPT given was the SOT, which generates equilibrium scores that compare the largest anterior-posterior movements of the subject over the trial with a theoretical limit for six sensory condition tasks. The sensory conditions were as follows: (1) eyes open with a fixed surface and visual surroundings, (2) eyes closed with a fixed surface, (3) eyes open with a fixed surface and sway referenced visual surroundings, (4) eyes open with a sway referenced surface and fixed visual field, (5) eyes closed with a sway referenced surface, and (6) eyes open with a sway referenced surface and visual surroundings (Figure 1). Each subject performed 3 trials on the Balance Master for each of the 6 sensory conditions, resulting in 18 equilibrium scores, ranging from 0 (touching a support surface, shifting feet, or falling) to 100 (little or no sway). From these equilibrium scores, 7 outcome measures were derived; the average of the 3 trials for each of the 6 conditions (equation [EQ] 1-
EQ6) and an overall composite score (COMP) calculated as a weighted average of the 18 individual equilibrium scores (conditions 1 and 2 are weighted $1 / 3$ as much as conditions 3 through 6 ).

Additionally, for this study "impairment" was defined as scoring at or below the 20th percentile of performance in a population of participants of similar age and with no history of disequilibrium (normative data provided by the administration manual).

\section{Statistical Analyses}

All statistical analyses were conducted using SPSS Statistics version 21.0 (IBM Corporation; Armonk, New York). Data were assessed for normality using the Shapiro-Wilk test. Since data were generally not normally distributed (or even transformed-normal), nonparametric Mann-Whitney U

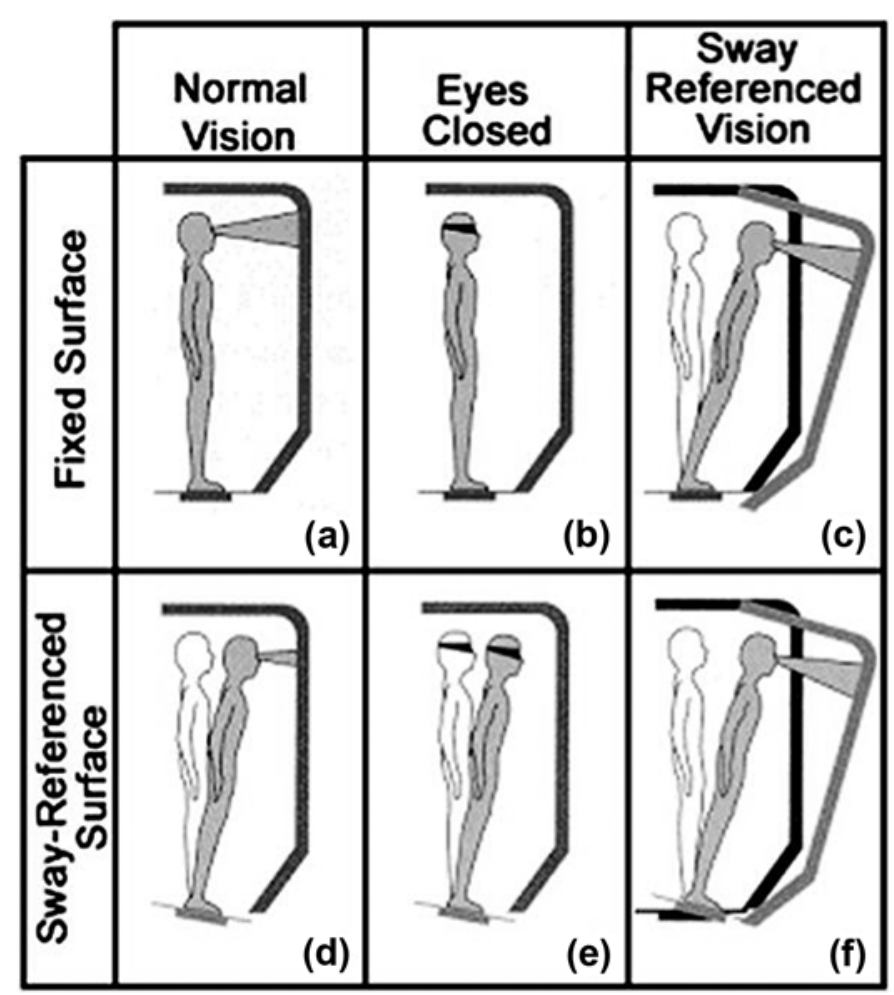

Figure 1.

Sensory Organization Test-six conditions. (a) Eyes open, fixed surface, and visual surround. (b) Eyes closed and fixed surface. (c) Eyes open, fixed surface, and sway referenced visual surround. (d) Eyes open, sway referenced surface, and fixed visual surround. (e) Eyes closed and sway referenced surface. (f) Eyes open, sway referenced surface, and visual surround. (Courtesy NeuroCom International Inc). 
and Kruskal-Wallis tests were used for between-group comparisons. When significant differences were found between groups, post hoc pairwise comparisons were performed using Dunn's procedure with a Bonferroni correction for multiple comparisons. Mann-Whitney $U$ tests were also performed on split data, and chi-square tests were applied to examine associations between participant cohorts and impairment.

\section{RESULTS}

\section{Demographic Data}

Of the 169 combat-exposed research participants, two participants' data were removed due to missing outcome measures (both unable to tolerate test), and one participant's data were removed because the balance scores did not pass the validity test for sufficient test effort (equilibrium scores for the more difficult conditions 5 or 6 were higher than for conditions 1, 2, or 3, pairwise) [41]. Of the 166 remaining participants with complete data, 160 were male. The mean age of the participants was $27.5 \mathrm{yr}$, with a standard deviation of $7.8 \mathrm{yr}$. Twenty-seven participants were African-American, 127 were white, and the remaining 12 self-identified as "other." The median time since the self-identified "worst" potential concussive event was $11.6 \mathrm{mo}$, with an interquartile range of 13.7.

Of the 166 participants, 33 had no blast mTBI, 47 had blast mTBI without PTA, and 86 had blast mTBI with PTA. Forty-six were diagnosed with PTSD. For the purposes of data analysis, four subgroups were created: no diagnosis of PTSD or blast mTBI with PTA $(n=65)$, diagnosis of blast mTBI with PTA but not PTSD $(n=55)$, diagnosis of PTSD but not blast mTBI with PTA $(n=25)$, and diagnosis of both blast mTBI with PTA and PTSD $(n=21)$ (Table 1).
The SOT findings for all 166 participants with complete data were analyzed to characterize impairments on the seven outcome measures and to contrast findings between the cohorts.

\section{No Blast mTBI Versus Blast mTBI (with PTA)}

To explore whether individuals with blast mTBI exhibit balance deficits (regardless of the presence of PTSD), Mann-Whitney $U$ tests were used to compare data for participants without blast mTBI $(n=80)$ and those with blast mTBI $(n=86)$ for each of the seven outcome measures. Only EQ3 showed a significant betweengroup difference $(p=0.006$; no blast $\mathrm{mTBI}$ median $=$ 92.3 , interquartile range $=4.67$; blast $\mathrm{mTBI}$ median $=$ 90.5 , interquartile range $=8.00$ ) .

Next, a chi-square test for each of the seven measures was used to test for association between impairment and blast mTBI diagnosis. A statistically significant association $(p<0.05)$ was found between blast mTBI diagnosis and impairment for COMP, as well as for EQ3 and EQ5 (Table 2).

\section{PTSD Versus No PTSD}

Similar analyses were performed for PTSD (regardless of the presence of blast mTBI). Mann-Whitney $U$ tests were used to compare data for participants not diagnosed with PTSD $(n=120)$ and participants diagnosed with PTSD $(n=46)$ for each of the seven outcome measures. The Mann-Whitney $U$ tests showed significant differences for the COMP $(p=0.01), \mathrm{EQ} 2(p=0.048), \mathrm{EQ} 4(p=$ $0.007)$, EQ5 $(p=0.03)$, and EQ6 $(p=0.02)$ outcomes. In addition, chi-square analyses showed a significant association between impairment and PTSD according to the same five measures (Table 3).

Table 1.

Descriptive data by diagnosis.

\begin{tabular}{|c|c|c|c|c|c|c|c|}
\hline Group & Diagnosis & $\begin{array}{c}\text { Male } \\
\text { (n) }\end{array}$ & $\begin{array}{l}\text { Female } \\
\text { (n) }\end{array}$ & $\begin{array}{c}\text { Age (yr), } \\
\text { mean } \pm \text { SD } \\
(n)\end{array}$ & $\begin{array}{c}\text { African } \\
\text { American } \\
\text { (n) }\end{array}$ & $\begin{array}{l}\text { White } \\
\text { (n) }\end{array}$ & $\begin{array}{c}\text { Other } \\
\text { Ethnicity } \\
(n)\end{array}$ \\
\hline $0(n=55)$ & $\begin{array}{l}\text { No PTSD and No Blast mTBI } \\
\text { with PTA }\end{array}$ & 50 & 5 & $26.3 \pm 7.6$ & 9 & 43 & 3 \\
\hline $1(n=65)$ & Blast mTBI with PTA only & 65 & 0 & $27.5 \pm 6.6$ & 8 & 52 & 5 \\
\hline $2(n=25)$ & PTSD only & 24 & 1 & $29.0 \pm 10.7$ & 2 & 19 & 4 \\
\hline $3(n=21)$ & $\begin{array}{l}\text { Blast mTBI with PTA and } \\
\text { PTSD }\end{array}$ & 21 & 0 & $29.0 \pm 7.8$ & 8 & 13 & 0 \\
\hline
\end{tabular}




\section{Controls, Isolated Blast mTBI, Isolated PTSD, and Comorbid Blast mTBI/PTSD}

Since 21 participants had both blast mTBI and PTSD, the interaction between mTBI and PTSD was investigated. First, Kruskal-Wallis tests were performed to determine whether there were differences in any of the equilibrium scores between the four mutually exclusive sets: participants diagnosed with neither blast mTBI nor PTSD (group 0; $n=55$ ), participants diagnosed only with blast mTBI (group $1 ; n=65$ ), participants diagnosed with only PTSD (group $2 ; n=25$ ), and participants diagnosed with both blast mTBI and PTSD (group 3; $n=21$ ).

The Kruskal-Wallis tests showed significant differences between groups for COMP, EQ3, EQ4, and EQ6 (see Figures $\mathbf{2}$ and $\mathbf{3}$ for results for COMP and EQ3.) Post hoc analyses indicated significant differences between groups 0 and 1 on EQ3, between groups 0 and 2 on EQ4, and between groups 0 and 3 on all four (COMP, EQ3,
EQ4, and EQ6). There were no between-group differences found for groups 1,2, and 3 in post hoc analyses.

To further investigate the interaction of blast $\mathrm{mTBI}$ and PTSD, individuals with comorbid conditions (group 3) were excluded and separate Mann-Whitney $U$ tests comparing the data from participants having neither diagnosis (group 0) with participants having either isolated blast mTBI (group 1) or isolated PTSD (group 2) were performed. The same tests were then performed excluding group 0 and comparing group 3 with either group 1 or group 2 to determine whether co-occurring diagnoses would mask or amplify findings from the isolated injury groups.

Mann-Whitney $U$ tests showed significant differences for COMP, EQ1, EQ2, EQ3, EQ4, and EQ6 when comparing group 0 (having neither diagnosis) to group 2 (isolated PTSD). In addition, using a chi-square measure of association, impairment had a significant association between group 0 and group 2 according to COMP, EQ2, EQ4, EQ5, and EQ6 (Table 4).

Table 2.

Association between blast mild traumatic brain injury (mTBI) with posttraumatic amnesia and impairment on Sensory Organization Test.

\begin{tabular}{|c|c|c|c|c|c|}
\hline Measure & Cut-Point & $\begin{array}{l}\text { No Blast mTBI, } \\
\text { \% Impaired }\end{array}$ & $\begin{array}{c}\text { Yes Blast mTBI, } \\
\text { \% Impaired }\end{array}$ & Chi-Square & $p$-Value* \\
\hline EQ1 & 92 & 21.25 & 24.42 & 0.236 & 0.63 \\
\hline EQ2 & 88 & 23.75 & 31.40 & 1.209 & 0.27 \\
\hline EQ3 & 88 & 20.00 & 33.72 & 3.949 & 0.047 \\
\hline EQ6 & 57 & 12.50 & 18.60 & 1.169 & 0.28 \\
\hline
\end{tabular}

Note: Bold indicates statistical significance.

*All cells have expected count greater than 5 .

$\mathrm{EQ}=$ equation.

Table 3.

Association between posttraumatic stress disorder (PTSD) and impairment on Sensory Organization Test.

\begin{tabular}{|c|c|c|c|c|c|}
\hline & Cut-Point & $\begin{array}{l}\text { No PTSD, } \\
\text { \% Impaired }\end{array}$ & $\begin{array}{l}\text { Yes PTSD, } \\
\text { \% Impaired }\end{array}$ & Chi-Square & $p$-Value* \\
\hline \multirow[t]{2}{*}{ Composite Score } & 75 & 22.50 & 39.13 & 4.654 & 0.03 \\
\hline & 92 & 20.83 & 28.26 & 1.039 & 0.31 \\
\hline \multirow[t]{2}{*}{ EQ2 } & 88 & 23.33 & 39.13 & 4.143 & 0.042 \\
\hline & 88 & 24.17 & 34.78 & 1.897 & 0.17 \\
\hline EQ4 & 57 & 11.67 & 26.09 & 5.235 & 0.02 \\
\hline
\end{tabular}

Note: Bold indicates statistical significance.

*All cells have expected count greater than 5 .

$\mathrm{EQ}=$ equation. 


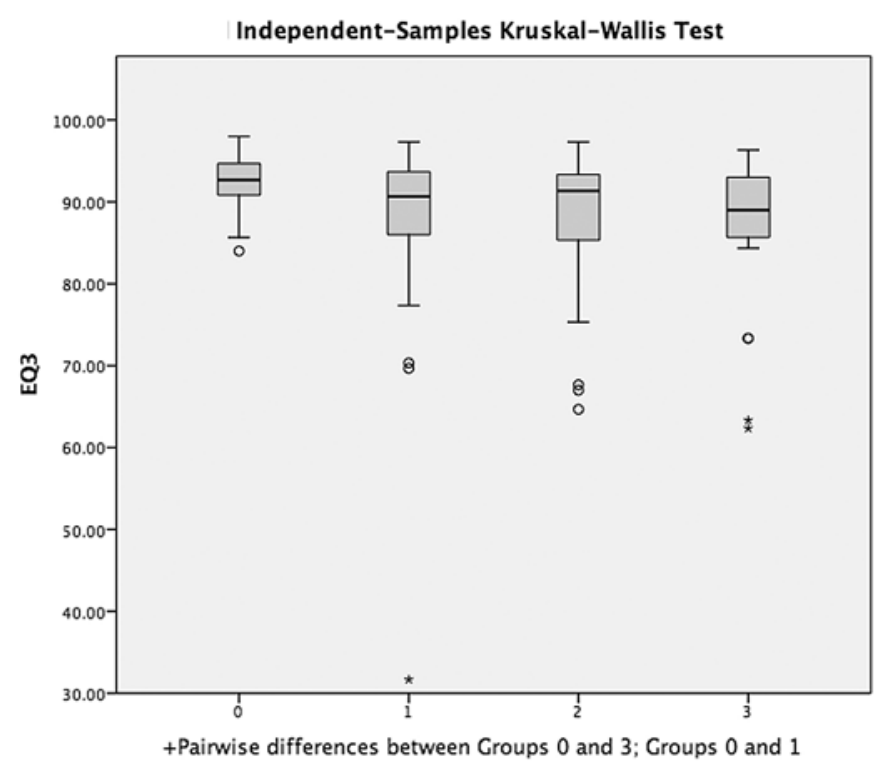

Figure 2.

Boxplots of equation 3 (EQ3) for groups $0,1,2$, and 3 (x-axis). Post hoc tests show groups 0 and 1 have significantly different medians. Additionally, groups 0 and 3 have significantly different medians.

In sharp contrast, Mann-Whitney $U$ tests showed no significant differential effect for PTSD when comparing data for participants diagnosed with isolated blast mTBI (group 1) to those with comorbid mTBI and PTSD (group 3). Likewise, impairment was not significantly associated with PTSD when only considering those with blast mTBI according on any of the seven measures (Table 4).

When the groupings were reversed and those having neither diagnosis (group 0) were compared with isolated blast mTBI (group 1), chi-square was significant for impairment according to COMP, EQ2, EQ3, EQ4, and EQ5 (Table 5). Again in sharp contrast, impairment was not significantly associated with mTBI when only considering those with PTSD according to any of the seven measures.

Finally, to determine whether participants exhibited differences between trials, Kruskal-Wallis tests were performed for groups 0 through 3 across the individual trials. No clinically significant results were found.

\section{DISCUSSION}

Traditionally, mTBI and PCS have been diagnosed by interview and physical examination proximate to the time

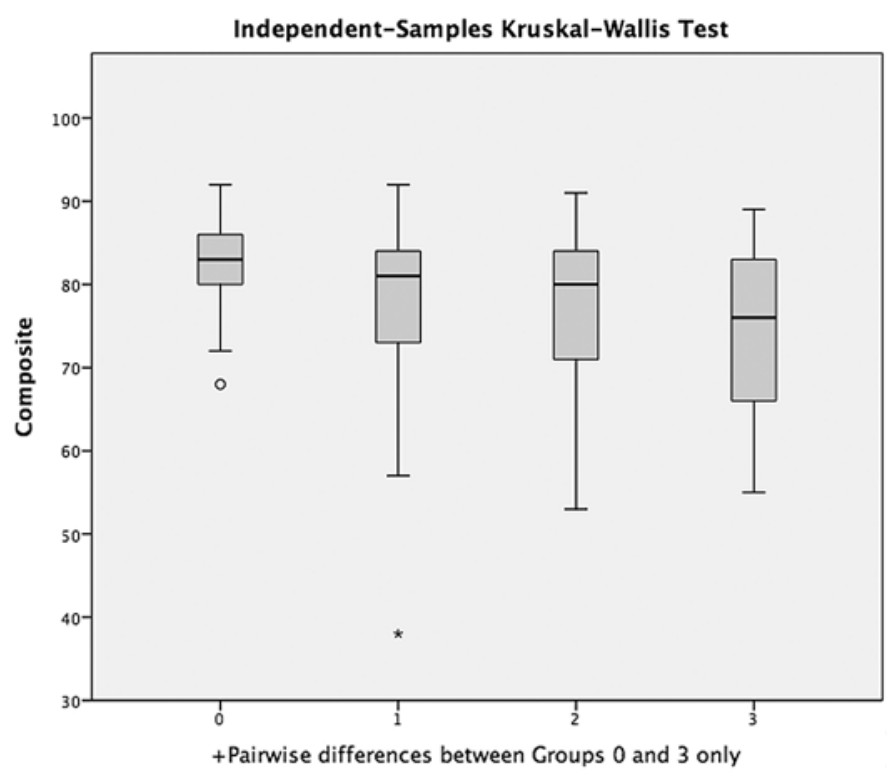

Figure 3.

Boxplots of composite score distributions for groups 0 (neither diagnosis), 1 (isolated blast mild traumatic brain injury [mTBI] with posttraumatic amnesia), 2 (isolated posttraumatic stress disorder [PTSD]), and 3 (comorbid mTBI and PTSD). Post hoc tests show groups 0 and 3 have significantly different medians.

of injury (e.g., in the emergency department); by interview and physical examination days, weeks, or months postinjury; and/or by neuroimaging. The ability to support the diagnosis of mTBI and assess the status of persistent difficulties from mTBI with physiological measures would improve the objectivity and reliability of diagnosis, allow for monitoring of recovery, and facilitate the assessment of treatment efficacy. The utility of assessing and defining balance deficits acutely after mTBI with CPT is well documented. Given the frequency of balance-related complaints and clinical findings following mTBI, identifying patterns of postural instability using CPT may represent a means of accurately identifying and quantifying the severity of balance deficits that may need treatment. CPT has also been suggested as an objective assessment tool for identifying and tracking the late effects of mTBI. However, previously chronically persisting balance deficits after combat blast mTBI have only been demonstrated in uncontrolled research studies and case reports. While the specific conditions and disorders that may contribute to postural instability may be of interest to patients and clinicians, this investigation focused on the use of the standardized SOT components of the Smart 
JRRD, Volume 52, Number 5, 2015

Table 4.

Association between posttraumatic stress disorder (PTSD) and balance (Sensory Organization Test) impairment.

\begin{tabular}{|c|c|c|c|c|c|c|c|c|}
\hline & \multicolumn{4}{|c|}{ No Blast mTBI $(n=80)$} & \multicolumn{4}{|c|}{ Yes Blast mTBI $(n=86)$} \\
\hline & $\begin{array}{l}\text { No PTSD, } \\
\text { \% Impaired } \\
(n=55)\end{array}$ & $\begin{array}{l}\text { PTSD, } \\
\% \text { Impaired } \\
(n=25)\end{array}$ & Chi-Square & $p$-Value* & $\begin{array}{l}\text { No PTSD, } \\
\text { \% Impaired } \\
(n=65)\end{array}$ & $\begin{array}{l}\text { PTSD, } \\
\% \text { Impaired } \\
(n=21)\end{array}$ & Chi-Square & $p$-Value* \\
\hline EQ1 & 16.36 & 32.00 & 2.511 & 0.11 & 24.62 & 23.81 & 0.006 & 0.94 \\
\hline EQ4 & 14.55 & 40.00 & 6.386 & 0.01 & & 42.86 & 1.038 & 0.31 \\
\hline EQ5 & 7.27 & 32.00 & 8.242 & 0.004 & & 38.10 & 1.434 & 0.23 \\
\hline EQ6 & 7.27 & 24.00 & 4.397 & 0.04 & & 28.57 & 1.823 & 0.18 \\
\hline
\end{tabular}

Table 5.

Association between blast mild traumatic brain injury (mTBI) with posttraumatic amnesia and balance (Sensory Organization Test) impairment.

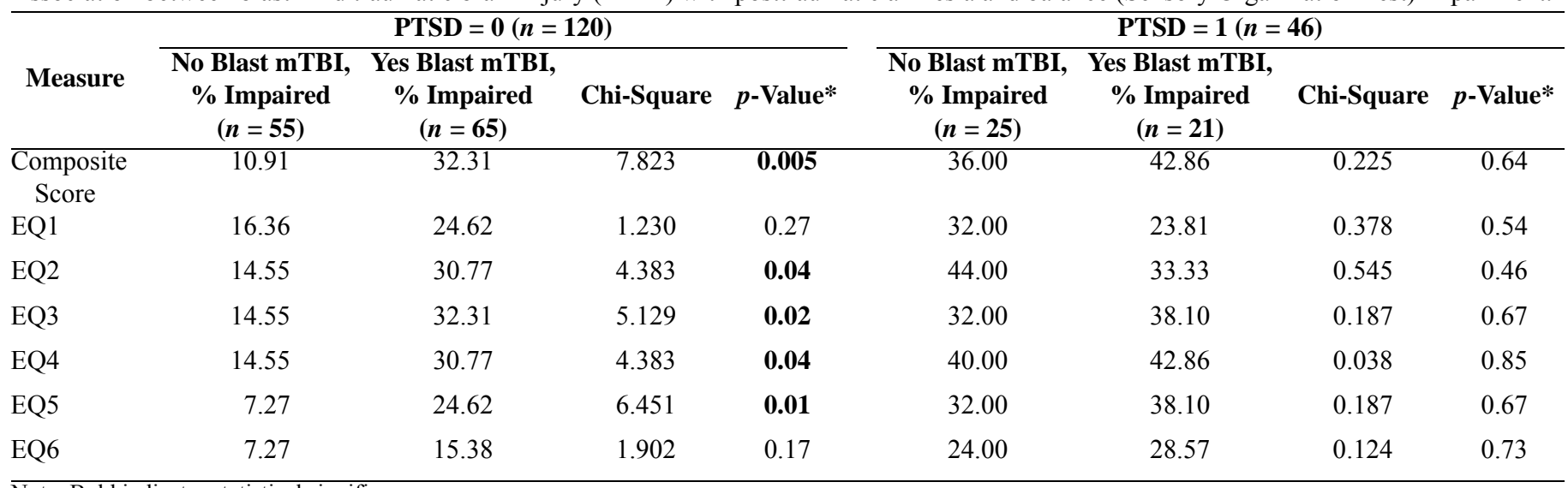

Note: Bold indicates statistical significance.

*No more than 1 cell per condition has expected count less than 5 .

$\mathrm{EQ}=$ equation, $\mathrm{PTSD}=$ posttraumatic stress disorder.

Balance Master to differentiate individuals with diagnoses of mTBI and/or PTSD.

This is the first controlled study to examine the use of CPT to objectively characterize chronic balance deficits after combat-related mTBI and to explore the utility of CPT in distinguishing between combat and blastexposed Veterans and SMs with and without mTBI and PTSD. Key findings of this investigation include (1) the characterization of balance deficits using CPT for participants having combat blast-associated mTBI with PTA or PTSD, (2) the confirmation of the amplification of CPT abnormalities in the face of both mTBI with PTA and PTSD, and (3) the identification of unique abnormalities on CPT for individuals with isolated mTBI with PTA or
PTSD. These findings have potential implications for diagnostics, classifying residual mTBI-related impairments, and establishing treatment needs for mTBI and PTSD related postural instability.

\section{CONCLUSIONS}

No Blast mTBI with PTA Versus Blast mTBI with PTA

Balance performance on CPT of participants having blast mTBI with PTA differed significantly from blastexposed controls having no mTBI or having mTBI without PTA, even in the context of high rates of PTSD. Uniformly, 
when surveying a cohort of combat-exposed participants with and without PTSD, the median of condition 3 (swayreferenced visual surround) equilibrium scores of participants having mTBI with PTA was significantly lower than the group of controls having either no mTBI or having mTBI without PTA. Analyses of the incidence of balance impairment also revealed differences between these two groups for both the COMP and condition 5 equilibrium scores.

Taken together, these results provide evidence that, on average, persons with a history of blast mTBI with PTA have reduced postural stability relative to those without it. They corroborate findings from sports concussion cohorts showing mTBI with PTA has a poorer prognosis than mTBI without PTA [42]. As one would expect given the high incidence of visual tracking deficits seen with mTBI [43], the CPT conditions targeting inaccurate visual feedback (condition 3) or deprived visual and proprioceptive feedback (condition 5) were particularly sensitive to mTBI with PTA. On the contrary, when normal visual inputs were available as in conditions 1 and 4, regardless of the presence of normal or altered proprioceptive input (a sense infrequently affected by mTBI), there were no group differences. While PTSD did have effects on postural instability as seen on CPT, the effects from mTBI were still noted over the entire cohort, suggesting these findings are specific to mTBI with PTA. These findings also support the work of Vanderploeg et al. that indicated long-lasting gait deficits after mTBI [27] and agree with the other recent reports regarding Veterans and SMs that posturography is among the most consistently affected measures of the vestibular and balance system after blast injury [44] and blast mTBI [29$31]$. The present findings extend these previous investigations with evidence that PTSD-related difficulties may not completely explain postural deficits in a military blast-exposed population. Additionally, the fact that these participants were not specifically referred for balance impairments or dizziness provides an unbiased perspective on balance deficits after blast mTBI and strengthens the generalizability of the findings. These unique and consistent findings may be useful in supporting the diagnosis of mTBI, monitoring recovery of postural deficits after mTBI, and assessing the effect of interventions for mTBI-related balance deficits.

\section{PTSD versus No PTSD}

Balance performance on CPT of participants with blastexposed PTSD differed significantly from blast-exposed controls without PTSD, even in the context of mTBI. Uniformly, when surveying a cohort of combat-exposed participants with and without blast mTBI with PTA, the median COMP and condition 2, 4, 5, and 6 (all of the eyes closed or moving platform conditions) equilibrium scores of participants with PTSD were lower than those without PTSD. Taken together, these results provide evidence that persons with a history of PTSD have reduced postural stability relative to those without PTSD. As one would expect, given the diffuse effect of PTSD on attention, concentration, and the integration of sensory inputs on overall functioning, postural abnormalities on CPT were seen on almost all elements of testing. Impairments during both eyes open and closed suggest a multilevel deficit involving integration of vestibular, somatosensory, and visual information (i.e., the entire balance system). These findings echo those of the Jacob et al. study of anxiety disorders and SOT [35], but in contrast to the specific deficits noted in that study for spatial anxiety in panic and agoraphobic disorders (condition 4 only), PTSD appears to have a global effect on postural stability that is not indicative of an overreliance on a particular information channel. This could reflect a general attentional bias toward the "imbalance" signal — a mismatch between the gravitational vertical and other sensory inputs and a form of danger signal. While mTBI did have effects on postural instability as seen on CPT, the effects from PTSD were noted over the entire cohort, suggesting a distinctly different profile from mTBI. As stated previously, the fact that these participants were not specifically referred for balance impairments or dizziness provides an unbiased perspective on balance deficits with PTSD and strengthens the generalizability of the findings.

\section{Neither Diagnosis, Isolated Blast mTBI with PTA, Isolated PTSD, and Comorbid mTBI/PTSD}

Postural instability impairments are seen in participants having isolated blast mTBI with PTA or PTSD and are identifiable when compared with combat-exposed controls with neither diagnosis. As demonstrated in Tables 2 and 4, while there appear to be unique patterns of CPT findings of abnormalities for both mTBI (condition 3) and PTSD (conditions 2, 4, and 6), there are also overlapping abnormalities (condition 5 and the overall COMP). Unfortunately, for comorbid mTBI/PTSD, there appear to be only nominal abnormalities on the full range of scores compared with both isolated mTBI and PTSD that prevent the simple differentiation of the two conditions using CPT. In particular, when the investigation of balance deficits 
after blast mTBI with PTA was limited to the subpopulation of participants with PTSD, no differences could be seen, suggesting PTSD masks the mTBI effects. The same result was found in the subpopulation of patients having blast mTBI with PTA: no median differences in scores were found between participants that were diagnosed with PTSD and those that were not because mTBI masked the effects of PTSD. Thus, the CPT findings may be useful to explain some percentage of the variance contributing to the differential diagnosis of mTBI and PTSD, but a more multimodal assessment tool may be needed to fully differentiate their effects.

Importantly, in individuals with both blast mTBI with PTA and PTSD, there is an overall amplification of abnormalities seen on CPT. Thus, individuals diagnosed with comorbid mTBI and PTSD would be expected to experience worse symptoms (dizziness), clinical findings (postural instability), and functional deficits (falls, inability to run) than those diagnosed with either of the conditions separately. Awareness of the cumulative effects of mTBI and PTSD on balance deficits may have clinical implications (e.g., earlier or more intensive use of vestibular rehabilitation). While a standard course of therapy to manage persistent postural instability due to distant blast mTBI with PTA may have a positive effect in individuals with isolated mTBI, clinicians may consider providing either a greater intensity or greater duration of these services in the face of concurrent PTSD; however, further research is needed to confirm this approach or to identify whether a different type of service may be needed altogether. While the specifics of therapeutic adjustments have not been elucidated, the ability of CPT to objectively (and differentially) identify abnormalities will assist in both developing and assessing the efficacy of these needed treatments.

Effective coordination of movement and balance involves a complex interaction of the sensory, motorprogramming, and musculoskeletal systems. Even minor impairments in integrating this information could ostensibly lead to significant disability [45]. Persistent balance deficits, even if mild, can complicate recovery from brain injury by contributing to emotional distress. Even mild dizziness and balance problems are more highly associated with psychiatric comorbidity than other disturbances of sensory function, such as hearing loss [46]. This relationship is believed to be due to the closely shared neural circuitry between spatial processing, balance control, and arousal [47] and may in part explain why severe TBI patients with balance problems have a poorer prognosis than those without [12]. Many SMs and Veterans with mTBI balance deficits also have PTSD, and it is known that the combination of psychiatric and physical morbidities is particularly disabling [48]. Thus, it is important to treat balance deficits when they occur, particularly if the individual is at risk for developing an emotional disorder. Therapies successful in alleviating balance problems may reduce long-term disability and also have downstream benefits for emotional outcomes.

This large, prospectively collected sample did not have selection bias based on complaints of imbalance or dizziness and represents the first sizable cohort of individuals with combat-associated, chronic mTBI with either a comparison sample of combat-exposed controls or assessment of the confounding effects of PTSD. Despite the strengths of the study, some limitations should be noted: (1) a single data set from one medical center (albeit recruited from several military treatment centers and a VAMC), (2) an almost exclusive male population, (3) no controls for other potential contributors of balance deficits (explained subsequently), and (4) no "gold standard" for confirming the late diagnosis of chronic mTBI. Future studies using this data set and others should also assess other specific characteristics seen with combat trauma, mTBI, and cohorts of SMs that may contribute to balance deficits such as substance use, other neuropsychiatric disorders (e.g., depression, anxiety), neurosensory symptoms (diplopia, tinnitus, hearing loss), somatic symptoms (insomnia, limb numbness, pain), and structural impairments (inner ear damage, perilymph fistula, peripheral nerve injury). The findings of this investigation should also be crossvalidated in additional cohorts, including ones with significant female participants.

\section{ACKNOWLEDGMENTS}

\section{Author Contributions:}

Study concept and design: D. X. Cifu, J. R. Wares, K. W. Hoke, L. Manning Franke, W. Walker, W. Carne.

Acquisition of data: W. Walker, L. Manning Franke.

Analysis and interpretation of data: D. X. Cifu, C. Ford-Smith, J. R. Wares, K. W. Hoke, L. Manning Franke, W. Walker, W. Carne. Drafting of manuscript: D. X. Cifu, J. R. Wares, K. W. Hoke, L. Manning Franke, W. Walker, W. Carne.

Critical revision of manuscript for important intellectual content: D. X. Cifu, J. R. Wares, K. W. Hoke, L. Manning Franke, W. Walker, W. Carne, C. Ford-Smith.

Statistical analysis: K. W. Hoke, J. R. Wares.

Obtained funding: D. X. Cifu, W. Walker, W. Carne. 
Study supervision: D. X. Cifu, W. Walker, W. Carne.

Financial Disclosures: The authors have declared that no competing interests exist.

Funding/Support: This material was based upon work supported by the U.S. Army Medical Research and Materiel Command (award no. W81XWH-13-2-0095). The U.S. Army Medical Research Acquisition Activity, Fort Detrick, Maryland, is the awarding and administering acquisition office. This material was also based upon work supported with resources and the use of facilities at the Hunter Holmes McGuire VAMC in Richmond, Virginia, and work supported in part by the Defense and Veterans Brain Injury Center, U.S. Army Medical Research and Materiel Command.

Additional Contributions: The authors would like to thank University of Richmond-funded undergraduates Hilary Briggs, Ruoping Shi, Weizhi $\mathrm{Wu}$, and Xiwen Zhou for their exemplary research assistance on this project.

Institutional Review: The institutional review boards of each institution/ facility and the Department of Defense's Human Research Protection Office approved this study.

Participant Follow-Up: The authors do not plan to inform participants of the publication of this study.

Disclaimer: The views, opinions, and/or findings contained in this article are those of the authors and should not be construed as an official VA or Department of Defense position, policy, or decision unless so designated by other official documentation.

\section{REFERENCES}

1. Owens BD, Kragh JF Jr, Wenke JC, Macaitis J, Wade CE, Holcomb JB. Combat wounds in Operation Iraqi Freedom and Operation Enduring Freedom. J Trauma. 2008;64(2): 295-99. [PMID:18301189] http://dx.doi.org/10.1097/TA.0b013e318163b875

2. Tanielian TL, Jaycox LH, editors. Invisible wounds of war: Psychological and cognitive injuries, their consequences, and services to assist recovery. Santa Monica (CA): RAND Corporation; 2008.

3. Meyer KS, Marion DW, Coronel H, Jaffee MS. Combatrelated traumatic brain injury and its implications to military healthcare. Psychiatr Clin North Am. 2010;33(4):783-96. [PMID:21093678] http://dx.doi.org/10.1016/j.psc.2010.08.007

4. DoD worldwide numbers for TBI [Internet]. Silver Spring (MD): Defense and Veterans Brain Injury Center; 2014. Available from: http://www.dvbic.org/dod-worldwide-numbers-tbi

5. Bazarian JJ, Atabaki S. Predicting postconcussion syndrome after minor traumatic brain injury. Acad Emerg Med. 2001;8(8):788-95. [PMID:11483453] http://dx.doi.org/10.1111/j.1553-2712.2001.tb00208.x

6. Ryan LM, Warden DL. Post concussion syndrome. Int Rev Psychiatry. 2003;15(4):310-16. [PMID:15276952] http://dx.doi.org/10.1080/09540260310001606692
7. Chamelian L, Feinstein A. Outcome after mild to moderate traumatic brain injury: The role of dizziness. Arch Phys Med Rehabil. 2004;85(10):1662-66. [PMID:15468028] http://dx.doi.org/10.1016/j.apmr.2004.02.012

8. Shumway-Cook A, Anson D, Haller S. Postural sway biofeedback: Its effect on reestablishing stance stability in hemiplegic patients. Arch Phys Med Rehabil. 1988;69(6): 395-400. [PMID:3377664]

9. Chaudhry H, Findley T, Quigley KS, Bukiet B, Ji Z, Sims T, Maney M. Measures of postural stability. J Rehabil Res Dev. 2004;41(5):713-20. [PMID:15558401] http://dx.doi.org/10.1682/JRRD.2003.09.0140

10. Hillier SL, Sharpe MH, Metzer J. Outcomes 5 years posttraumatic brain injury (with further reference to neurophysical impairment and disability). Brain Inj. 1997;11(9):661-75. [PMID:9376834] http://dx.doi.org/10.1080/026990597123214

11. Pogoda TK, Hendricks AM, Iverson KM, Stolzmann KL, Krengel MH, Baker E, Meterko M, Lew HL. Multisensory impairment reported by veterans with and without mild traumatic brain injury history. J Rehabil Res Dev. 2012; 49(7):971-84. [PMID:23341273]

http://dx.doi.org/10.1682/JRRD.2011.06.0099

12. Duong TT, Englander J, Wright J, Cifu DX, Greenwald $\mathrm{BD}$, Brown AW. Relationship between strength, balance, and swallowing deficits and outcome after traumatic brain injury: A multicenter analysis. Arch Phys Med Rehabil. 2004;85(8):1291-97. [PMID:15295755] http://dx.doi.org/10.1016/j.apmr.2003.11.032

13. Walker WC, McDonald SD. Does neurologic examination during inpatient rehabilitation help predict global outcome after nonpenetrating traumatic brain injury? PM R. 2011; 3(1):6-12. [PMID:21257127] http://dx.doi.org/10.1016/j.pmrj.2010.11.001

14. Pickett TC, Radfar-Baublitz LS, McDonald SD, Walker WC, Cifu DX. Objectively assessing balance deficits after TBI: Role of computerized posturography. J Rehabil Res Dev. 2007;44(7):983-90. [PMID:18075955] http://dx.doi.org/10.1682/JRRD.2007.01.0001

15. Cavanaugh JT, Guskiewicz KM, Giuliani C, Marshall S, Mercer V, Stergiou N. Detecting altered postural control after cerebral concussion in athletes with normal postural stability. Br J Sports Med. 2005;39(11):805-11. [PMID:16244188] http://dx.doi.org/10.1136/bjsm.2004.015909

16. Guskiewicz KM. Assessment of postural stability following sport-related concussion. Curr Sports Med Rep. 2003; 2(1):24-30. [PMID:12831673] http://dx.doi.org/10.1249/00149619-200302000-00006

17. McCrea M, Guskiewicz KM, Marshall SW, Barr W, Randolph C, Cantu RC, Onate JA, Yang J, Kelly JP. Acute effects and recovery time following concussion in collegiate football players: The NCAA Concussion Study. 
JAMA. 2003;290(19):2556-63. [PMID:14625332]

http://dx.doi.org/10.1001/jama.290.19.2556

18. Chou LS, Kaufman KR, Walker-Rabatin AE, Brey RH, Basford JR. Dynamic instability during obstacle crossing following traumatic brain injury. Gait Posture. 2004;20(3): 245-54. [PMID:15531171] http://dx.doi.org/10.1016/j.gaitpost.2003.09.007

19. Kaufman KR, Brey RH, Chou LS, Rabatin A, Brown AW, Basford JR. Comparison of subjective and objective measurements of balance disorders following traumatic brain injury. Med Eng Phys. 2006;28(3):234-39. [PMID:16043377] http://dx.doi.org/10.1016/j.medengphy.2005.05.005

20. Cripps A, Livingston SC. The value of balance-assessment measurements in identifying and monitoring acute postural instability among concussed athletes. J Sport Rehabil. 2013; 22(1):67-71. [PMID:23037313]

21. Rubin AM, Woolley SM, Dailey VM, Goebel JA. Postural stability following mild head or whiplash injuries. Am J Otol. 1995;16(2):216-21. [PMID:8572122]

22. Baker CS, Cinelli ME. Visuomotor deficits during locomotion in previously concussed athletes 30 or more days following return to play. Physiol Rep. 2014;2(12):e12252. [PMID:25539832] http://dx.doi.org/10.14814/phy2.12252

23. Fait P, McFadyen BJ, Swaine B, Cantin JF. Alterations to locomotor navigation in a complex environment at 7 and 30 days following a concussion in an elite athlete. Brain Inj. 2009;23(4):362-69. [PMID:19274521] http://dx.doi.org/10.1080/02699050902788485

24. Powers KC, Kalmar JM, Cinelli ME. Recovery of static stability following a concussion. Gait Posture. 2014;39(1): 611-14. [PMID:23810088] http://dx.doi.org/10.1016/j.gaitpost.2013.05.026

25. Hoge CW, McGurk D, Thomas JL, Cox AL, Engel CC, Castro CA. Mild traumatic brain injury in U.S. Soldiers returning from Iraq. N Engl J Med. 2008;358(5):453-63.

[PMID:18234750] http://dx.doi.org/10.1056/NEJMoa072972

26. Terrio H, Brenner LA, Ivins BJ, Cho JM, Helmick K, Schwab K, Scally K, Bretthauer R, Warden D. Traumatic brain injury screening: Preliminary findings in a US Army Brigade Combat Team. J Head Trauma Rehabil. 2009; 24(1):14-23. [PMID:19158592] http://dx.doi.org/10.1097/HTR.0b013e31819581d8

27. Vanderploeg RD, Curtiss G, Luis CA, Salazar AM. Longterm morbidities following self-reported mild traumatic brain injury. J Clin Exp Neuropsychol. 2007;29(6):585-98. [PMID:17691031] http://dx.doi.org/10.1080/13803390600826587

28. Hoffer ME, Balaban C, Gottshall K, Balough BJ, Maddox MR, Penta JR. Blast exposure: Vestibular consequences and associated characteristics. Otol Neurotol. 2010;31(2):
232-36. [PMID:20009782]

http://dx.doi.org/10.1097/MAO.0b013e3181c993c3

29. Akin FW, Murnane OD. Head injury and blast exposure: Vestibular consequences. Otolaryngol Clin North Am. 2011;44(2):323-34, viii. [PMID:21474007] http://dx.doi.org/10.1016/j.otc.2011.01.005

30. Cohen JT, Ziv G, Bloom J, Zikk D, Rapoport Y, Himmelfarb MZ. Blast injury of the ear in a confined space explosion: Auditory and vestibular evaluation. Isr Med Assoc J. 2002;4(7):559-62. [PMID:12120473]

31. Scherer MR, Shelhamer MJ, Schubert MC. Characterizing high-velocity angular vestibulo-ocular reflex function in service members post-blast exposure. Exp Brain Res. 2011; 208(3):399-410. [PMID:21113582] http://dx.doi.org/10.1007/s00221-010-2490-1

32. Cifu DX, Taylor BC, Carne WF, Bidelspach D, Sayer NA, Scholten J, Campbell EH. Traumatic brain injury, posttraumatic stress disorder, and pain diagnoses in OIF/OEF/OND Veterans. J Rehabil Res Dev. 2013;50(9):1169-76.

[PMID:24458958]

http://dx.doi.org/10.1682/JRRD.2013.01.0006

33. Sundin J, Fear NT, Iversen A, Rona RJ, Wessely S. PTSD after deployment to Iraq: Conflicting rates, conflicting claims. Psychol Med. 2010;40(3):367-82. [PMID:19671210]

http://dx.doi.org/10.1017/S0033291709990791

34. Gupta MA. Review of somatic symptoms in post-traumatic stress disorder. Int Rev Psychiatry. 2013;25(1):86-99.

[PMID:23383670] http://dx.doi.org/10.3109/09540261.2012.736367

35. Jacob RG, Redfern MS, Furman JM. Space and motion discomfort and abnormal balance control in patients with anxiety disorders. J Neurol Neurosurg Psychiatry. 2009;80(1): 74-78. [PMID:18653552] http://dx.doi.org/10.1136/jnnp.2007.136432

36. DoD/VA code proposal final-508 compliant [Internet]. Atlanta (GA): CDC; 2008. Available from: http://www.cdc.gov/nchs/data/icd/Sep08TBI.pdf

37. Elhai JD, Gray MJ, Kashdan TB, Franklin CL. Which instruments are most commonly used to assess traumatic event exposure and posttraumatic effects?: A survey of traumatic stress professionals. J Trauma Stress. 2005;18(5): 541-45. [PMID:16281252] http://dx.doi.org/10.1002/jts.20062

38. Sheehan DV, Lecrubier Y, Sheehan KH, Amorim P, Janavs J, Weiller E, Hergueta T, Baker R, Dunbar GC. The MiniInternational Neuropsychiatric Interview (M.I.N.I.): The development and validation of a structured diagnostic psychiatric interview for DSM-IV and ICD-10. J Clin Psychiatry. 1998;59(Suppl 20):22-33, quiz 34-57. [PMID:9881538]

39. Walker WC, McDonald SD, Franke LM. Diagnostic accuracy of Posttraumatic Stress Disorder Checklist in blast 
exposed military personnel. J Rehabil Res Dev. 2014; 51(8):1203-16.

40. Weathers FW, Keane TM, Davidson JR. Clinicianadministered PTSD scale: A review of the first ten years of research. Depress Anxiety. 2001;13(3):132-56.

[PMID:11387733] http://dx.doi.org/10.1002/da.1029

41. Cevette MJ, Puetz B, Marion MS, Wertz ML, Muenter MD. Aphysiologic performance on dynamic posturography. Otolaryngol Head Neck Surg. 1995;112(6):676-88. [PMID:7777351] http://dx.doi.org/10.1016/S0194-5998(95)70175-3

42. Collins MW, Iverson GL, Lovell MR, McKeag DB, Norwig J, Maroon J. On-field predictors of neuropsychological and symptom deficit following sports-related concussion. Clin J Sport Med. 2003;13(4):222-29. [PMID:12855924] http://dx.doi.org/10.1097/00042752-200307000-00005

43. Cifu DX, Wares JR, Hoke KW, Wetzel PA, Gitchel G, Carne W. Differential eye movements in mild traumatic brain injury versus normal controls. J Head Trauma Rehabil. 2015;30(1):21-28. [PMID:24695263] http://dx.doi.org/10.1097/HTR.0000000000000036

44. Scherer M, Burrows H, Pinto R, Somrack E. Characterizing self-reported dizziness and otovestibular impairment among blast-injured traumatic amputees: A pilot study. Mil Med. 2007;172(7):731-37. [PMID:17691686] http://dx.doi.org/10.7205/MILMED.172.7.731

45. Basford JR, Chou LS, Kaufman KR, Brey RH, Walker A, Malec JF, Moessner AM, Brown AW. An assessment of gait and balance deficits after traumatic brain injury. Arch Phys Med Rehabil. 2003;84(3):343-49. [PMID:12638101] http://dx.doi.org/10.1053/apmr.2003.50034

46. Yardley L. Overview of psychologic effects of chronic dizziness and balance disorders. Otolaryngol Clin North Am.
2000;33(3):603-16. [PMID:10815039]

http://dx.doi.org/10.1016/S0030-6665(05)70229-2

47. Balaban CD, Thayer JF. Neurological bases for balanceanxiety links. J Anxiety Disord. 2001;15(1-2):53-79.

[PMID:11388358] http://dx.doi.org/10.1016/S0887-6185(00)00042-6

48. Yardley L, Burgneay J, Nazareth I, Luxon L. Neuro-otological and psychiatric abnormalities in a community sample of people with dizziness: A blind, controlled investigation. J Neurol Neurosurg Psychiatry. 1998;65(5):679-84.

[PMID:9810937]

http://dx.doi.org/10.1136/jnnp.65.5.679

Submitted for publication August 26, 2014. Accepted in revised form April 1, 2015.

This article and any supplementary material should be cited as follows:

Wares JR, Hoke KW, Walker W, Manning Franke L, Cifu DX, Carne W, Ford-Smith C. Characterizing effects of mild traumatic brain injury and posttraumatic stress disorder on balance impairments in blast-exposed servicemembers and Veterans using computerized posturography. J Rehabil Res Dev. 2015;52(5):591-604. http://dx.doi.org/10.1682/JRRD.2014.08.0197

ResearcherID: Laura Manning Franke, PhD: F-2670-2012

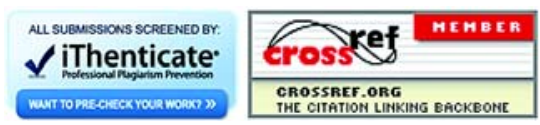


